\title{
Controlling and Monitoring of Industrial Parameters Through Cloud Computing and HMI Using OPC Data Hub Software
}

\author{
Waqas Ahmed Siddique, Muhammad Farhan Siddiqui, Awais Khan \\ Jumani* and Asad Ali Shaikh \\ Faculty of Science and Technology, ILMA University Karachi, Sindh, Pakistan
}

\section{Article Type: Article \\ Article Citation: Waqas Ahmed Siddique, Muhammad Farhan Siddiqui, Awais Khan Jumani, Asad Ali Shaikh. Controlling and monitoring of industrial parameters through cloud computing and HMI using OPC data hub software. Indian Journal of Science and Technology. 2020; 13(02), 114-126. D0l: 10.17485/ijst/2020/ v013i02/148768}

Received date: November 9, 2019

Accepted date: December 5, 2019

*Author for correspondence: Awais Khan Jumani $\mathbf{V}$ awaisjumani@ yahoo.com 9 Faculty of Science and Technology, ILMA University Karachi, Sindh, Pakistan

\begin{abstract}
Motivation: Controlling and monitoring of the whole process of industry is very difficult from a single place. Many workers required in different places of the plant to monitor, analyse, and gather data and to perform specific function accordingly. Problem: These gathering of data cause us our precious time. Sometimes due to this delay, many accidents occur like fire, leaking of different dangerous gases or materials, etc. Many monitoring tools and methods were developed to give solution for gathering data, but still workers were needed on the plant side to complete the task like powering on or off the system. Methods: This cloud-based industrial system controlling and monitoring application is designed not only to help in gathering data but also in controlling of different parameters of industry in a single application. Findings: This gathering is done via the cloud; Human Machine Interface (HMI) is linked to a database so that everyone can easily understand the working status of the plant. These data can be controlled and monitored from everywhere and from every device which has internet availability. Here we are using Siemens manufactured digital module of Programmable Logic Controller (PLC) s7-200. Without any internet module of PLC, we are sending our data over cloud to be monitored and controlled from all over the world. Application: The next step of this application will be receiving notifications via email or SMS whenever a parameter is changed.
\end{abstract}

Keywords: Industrial Automation, Controlling, Monitoring, $\mathrm{HMI}$, Open Platform Communications (OPC) Server, Programmable Logic Device.

\section{Introduction}

There are lots of automation techniques implemented and used to provide ease in our work, especially the idea of automation of the industry and its system with the exchange of data over a secure GSM [1]. Mousam proposed industrial automation using 8051 
microcontrollers [2], in which another idea for automation of industry was presented. But still problem left, when going for automation through micro-controller heating factor comes in our way, as 8051 chip is not built for industrial environment. Whereas while working through GSM, the person working or controlling industry required smart phones of high functionality so that the command of proceeding can be sent to run the system, which is difficult for everyone to buy and keep in everywhere.

A lot of research has been done and published in the field of automation for different parameters used in industries. In Ref. [3], Madan and Reddy provided information that any plant which is operated manually can be transformed into the automated plant in order to get the highest amount of accuracy in work, in order to get the maximum amount of output or we can say that highest efficiency and to save the precious time of user. In his work, he is using GSM modems to receive all the important data/information about working loads and about the user's location from any place and time. Similarly, author [4] provides a vast study about automation level and different types of automations used in industries using CNC, CAM, and FMS. In another research [5], author presented the quantitatively verified study with the use of text mining tool also known as a WORD Smith Tool. The study determines on how we can implement the RAS and what the critical success factors for such implementations are. Moreover, Meenu [6] had given information about industrial automation on the manufacturing side. It presents with pros and cons of transforming the industries into automation, which was based on different types of pilot and Delphi studies. Correspondingly, Gade [7] worked on integration of industries and making them automate while using computer vision systems presented topics that can help in impacts of machine vision and different types of research field's in industrial automations. These impacts can be direct or indirect on vision of the machine. In Ref. [8], Kumar and Goudar proposed a system for controlling industrial parameter using cellular phones over GSM network. In Ref. [9], authors worked on automation and security offered a complete real-time monitoring and controlling system using the global system for mobile and short messaging service for input and to take feedback of the system. In Ref. [10], Prasad et al. proposed the way of automating the industries and other parameters using 8051 microcontrollers. In Ref. [11], Kaur et al. gave the way of detecting different parameters of industries like smoke, temperature, fire, explosion, and leakage of gas and many other using a microcontroller and display the output on led screen. In Ref. [12], his work on automation system with security using microcontroller gave the ideas of implementing security and automation using a microcontroller. In Ref. [13], his work on agenda related to cloud computing shows how quickly we can be upgrading of industrial automation occur and what are their efforts. In another work [14], Javaid et al. gave an environment for powerful computing storage for its end user on low cost its issues and their conclusions. In Ref. [15], his research namely industrial environment monitoring and controlling system using android application proposed a GUI-based system which detect and look after numbers of sensors. This system can also be used to run many different machines of industry. It also had the feature of environment checking via manually or automatically using android based application. In Ref. [16], her study described a method to control system using GSM. This system will help the user to know about the working condition of the system and also indicate if there is any fault or issue related to the system 
occur. In Ref. [17], Steenbruggen et al. gave a comparative approach for home security from remote location through wireless network system and by using GSM also. This system is using low power and is developed by using WSN and GSM technologies. It contains microcontroller based wireless sensors for different parameters or machineries used in home. For security purpose, an alarm system is made using ZIGBEE chip. In Ref. [18], Dillon et al. worked on controlling power proposed a smart grid for monitoring and controlling of power utilization. It covers the area for communication of low data rate having minimum power consumption. It controls most of the user friendly home appliances and their power on/off using internet. In Ref. [19], Foster et al. gave the idea of home automation using smart GSM. In it, the focus was on the functionality and working of the GSM protocol that authorized the user to monitor and control system far away from the bandwidth used in home. In this system, user or controller can easily get response or the status from the home appliances attached to the protocols, that weather they are on or power off. In Ref. [20], her research proposed an idea of intelligent home. In which she showed about home security system having instant response. In this, she proposed a password based security for home. In it, the controller of the house had access to switch on or off the lights and other parameters of the house. In it, the feature of alert SMS is also given, that is in case of emergencies like fire, gas leakage, robbery or other issues related to home a SMS is initiated to the owner or the user of the service. In Ref. [21], Birman et al. reviewed the application that gives versatile phone knowledge from GSM network for traffic parameters and metropolitan and geographical sketch evolution. This work gave organized rundown of the project working on the use of the data taken from the cell phone network to get coordinates and to know traffic approximation of the single user. In Ref. [22], Victor shows remote working of industrial parameters over cloud using voice activation. In this, he gives the idea of controlling of industry and converting of natural spoken language into the codes that control or process the working of the industry. In Ref. [23], Maiti and Sivanesan provided a case study, in which the working on end to end automation and transferring of data through cloud is discussed. In Ref. [24], Bauer proposed the security system and burglary prevention stratagems through ad-hoc wireless home automation system with suite intrusion system. In Ref. [24], Bauer worked on cloud automation and economic efficiency which gives the mechanism of producing efficient output for the organization and also for the improvement of performance and quality. In Ref. [25], Vishal Kumar et al. compared work on fog computing and cloud computing. Fog provides focal points for the improve competence, better protection and carrying of information in an organized manner from one place to another. It also shows that fog is better to use instead of transferring the all of our information on the cloud. Zhihao [26] reported the architecture, its implementation and testing of OLE for process control on data access specification. In Ref. [27], Memon et al. studied the big data and showed the analytic structure of Big-Data. In Ref. [28], Rehman et al. worked on radio frequency, where all data can be fetched through simple tool. In Ref. [29], Jumani et al. worked on software tool because that software work like technique. As well as, data HUB software works for controlling. According to Ref. [30], the work has clustered the operating system where it adjusts the setting inside any software. In Ref. [31], Surahio et al. worked on speech deduction. When the user gives the data through voice than it converts into voice. 
Moreover, Laghari [32] in this research, the author has worked on RFID toll deduction system. Where it controls the automatic toll of any booth. Furthermore, in Ref. [33], Laghari shows the cloud-based data travelling, so it works on cloud as well as, control it from anywhere.

In this study, the controlling and monitoring of industrial parameters through cloud computing and HMI using OPC data hub software provide a solution to almost every solution. This work is not only for monitoring but also controlling of data through a single PC. Workers do not need to visit machines again and again to take reading to on or off the system; everything is provided on the PC. It helps in reading manual intervention, reduce in redundancy. It helps in improving the existing service, increase in efficiency and accuracy. All the outputs are in real time.

\section{Methodology}

The nature of the project is the mixture of both hardware and software; in which hardware part contains both mechanical and electronic components. Viewing the mechanical part of this research depends upon the table structure having four containers: solenoid valve, level detector for level maintain and conveyor belt with its driving motor. This setup is aligned in order to meet all aspects of practically real industrial requirements. In it, the electronic part consists of fab array PLC, microcontroller, power supply, different types of sensors and many other components which can be placed in as a secondary component list. PLC logic diagram and HMI screen are part of software as these are required to process the software side function.

This autonomous project has two modes of operation; one is the automatic and the other mode of operation is manual. The PLC takes input from HMI and gives the signal to PLC via communication port (serial communication port) to perform the whole process either automatic or manual mode. When the input signal is received by PLC, it starts the process using the logic diagram file which is uploaded in PLC register. The HMI and PLC are communicating which each other using a communication card or dongle.

In Figure 1, flow diagram shows the working or we can say the flow of data from the start of the project to the end. In this, the first step is to fill the main tank up to the required level. This level is checked and collected data through the level sensor. The material comes from the subtank with the help of solenoid valves. In the main tank, we mix the material comes from different subtanks via heating or mixer. After checking that the mixing or heating reached the required level, we allow them to be filled in bottles or containers which are moving on the conveyor belt. A motorized valve is installed so that the exact amount, level or quantity or material is filled in the bottle. There is a proximity sensor installed to stop the bottle exactly under the motorized valve. After filling we check the level of the main tank and do it till the required number of product is produced or we reached the lowest level of material in the main tank.

Some of the main ingredients of this work are that it is based on totally real time. It has a self-designed flow meter that provides accurate reading. In it, an easy path is provided to the user, who monitors and controls all parameters through visible display or in words with 


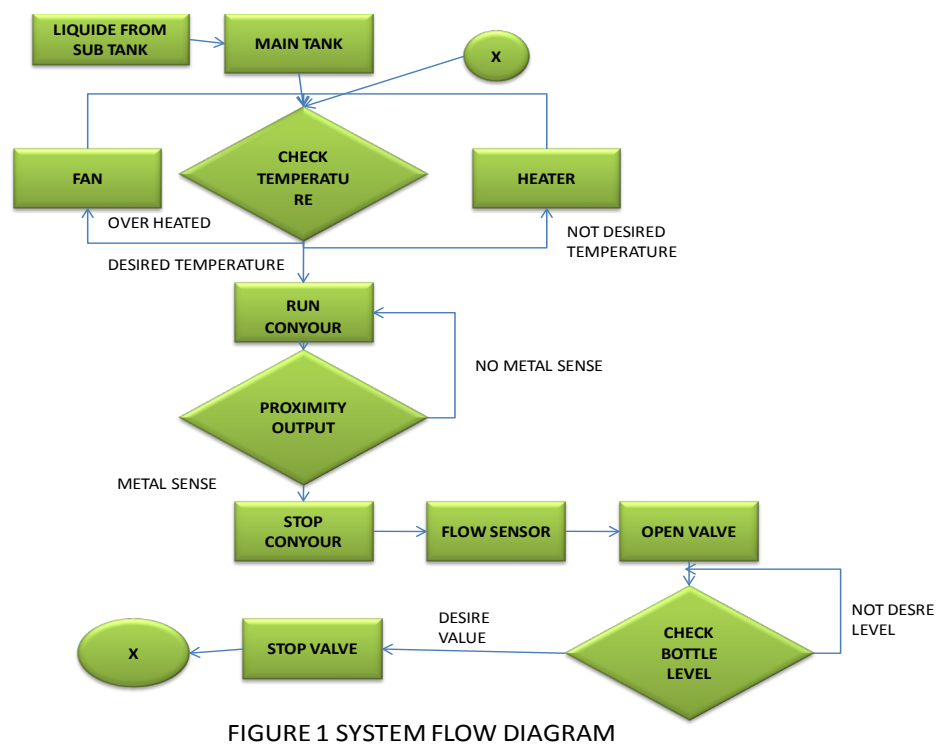

FIGURE 1. System flow diagram.

the help of HMI. In it, all parameters can be easily operated manually or automatically just a single press on the display. Security is insured through a password. All the safeguards that are important are actualized within the system, like level detection of fluid, overheating, proper blending of mixture, correct position of filling through the sensor. Reprogramming is the major point by which the numerous tasks can be done.

The methodology of our system defines the three mode of operation. The automation project has three modes of operation.

- Automatic mode of operation

- Manual mode of operation.

- Direct mode of operation.

\subsection{Automatic Mode}

When using the first mode of operation, the automatic one. The procedure or sequence of the project is when plugging the PLC plug on the electric board and make them on and then move the selector switch onto the position of automatic mode. As a fab array, PLC starts it first check its loop test and then using comm. Check button on HMI screen the communication between HMI and PLC will be tested. As soon as the automatic start button is press on the HMI screen, the whole process start, it contains three transparent plastic containers that contain three any different liquid. Solenoid valve is attached to these three containers. Solenoid valve will operate through programming via PLC. First solenoid wills came in operating condition and remain open until the given specified time is completed. Then the second solenoid will operate when the first solenoid is off and it will remain on until its specified time is not completed; now the third solenoid will operate 
and repeat the same procedure. These solenoid valves are time based are used to fill the center container. The center container is milky white plastic. After solenoid operation mixing motor will start its operation to mix the liquid in the center milky container. The center container contains a heater to achieve a specific temperature so it became on and raise the temperature of the liquid. A level sensor is also attached to maintain a liquid at particular level. After that, the conveyor belt will start to move. When the empty beaker is placed on the rotating conveyor belt, the beaker starts moving with belt. When the beaker comes in front of position Sensor or proximity sensor, a signal goes to the PLC, which causes the motor to stop \& after some delay fourth solenoid valve opens \& filling starts. After some delay, the Solenoid valve stops causing stop to fill the beaker \& after few more seconds' conveyor starts. This process continues in a loop \& filling purpose is accomplished.

\subsection{Manual Mode}

When using the second mode of operation, the manual mode. The procedure or sequence of the project is when plugging the PLC plug on the electric board and make them on and then move the selector switch onto the position of manual mode. As fab array PLC start it first check its loop test and then using comm. Check button on HMI screen the communication between HMI and PLC will be tested. In this mode, you can activate each and every component of the project by pressing its button on the HMI screen. For example, if we want to open the third solenoid all we have to do is just press the button on HMI indicating third solenoid and third solenoid came in working condition and by pressing one more time it will stop the operation of third solenoid. Each and every device can be manually on and off using the same above procedure.

\subsection{Direct Mode}

The direct mode of operation is only an automatic mode. The direct mode of operation is a mode in which the whole project will run without personal computer or HMI or any input from any input device. In this mode just plug the fab PLC pluck into the electric board and move the selector switch onto the position of automatic mode. So, the PLC will start following his automatic operation. No communication cable or communication circuit or dongle is required to run in direct mode.

Figure 2 displays the block diagram of the project. Here we have PC which is working as a server for data to store and process. We have Wi-Fi device as we are not using the $\mathrm{Wi}-\mathrm{Fi}$ module of the PLC. Then on the next, we have PLC connected to the server and all the industrial parameters attached to it. Here S1, S2, S3 shows the three switches whereas M1 and M2 show the connection of the motor to the PLC and H1 shows the heater or mixture, depend on the instrument used in the main tank to mix the material/data. In it, we show that the PLC is taken its input from different types of sensor such as temperature sensor, flow sensor, level detector, and proximity sensor. In it, we show that we can display output and can take input from any place and from any device that have internet facility in it. We use different tools' in our project. Some of which are as follows: 


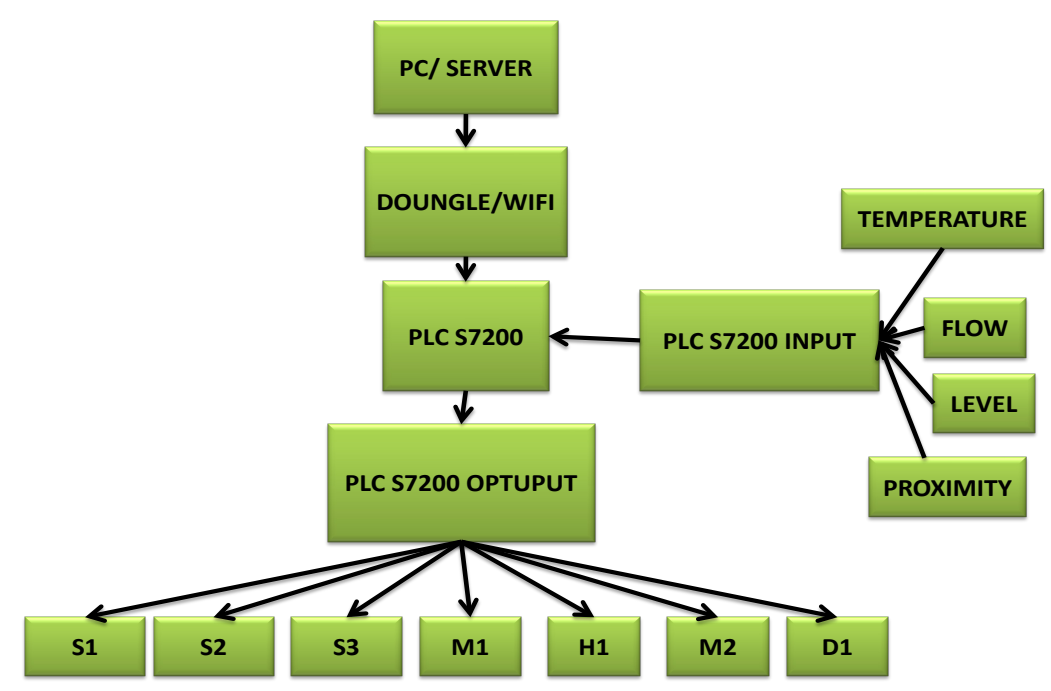

FIGURE 2. Block diagram.

- Micro win PLC S7-200 Siemens PLC software

- PC-Access (OPC)

- Cogent Hub SCADA \& HMI

- Orcad 9.0

\subsection{Micro Win PLC}

STEP7-Micro/Win is helping us in saving our most valuable time, money and energy if we program our data on it. This tool is simple in used like any other normal windowsbased application. In it, we have all the required tools that can be helpful in proper and suitable programming. It is the newest version which is appropriate to work on different level or versions of windows like WIN2000, version of XP, and much other upper level of operating systems. It provides us other things to work on as well like segmented data memory, etc. It also helps in diagnosing function as well as a user specific LED, history of error, editing in run time and facility of online downloads (Figure 3).

\subsection{The STEP 7-Micro/WIN Programming Wizards}

This programming wizard gives simple graphical assistance to complex tasks as well as automatic testing services to all the memory operations exists. It creates commented programming blocks and others. STEP 7-Micro/WIN helps us in getting the right wizard for any type of complex automation solution.

\subsection{PC-access (OPC)}

It is a cheap OPC server, which gives connectivity to the siemen- micro PLC over any version of S7-200 PLC protocols (i.e. MPI, DP, ETHERNET, PPI, and modem). Zhihao 


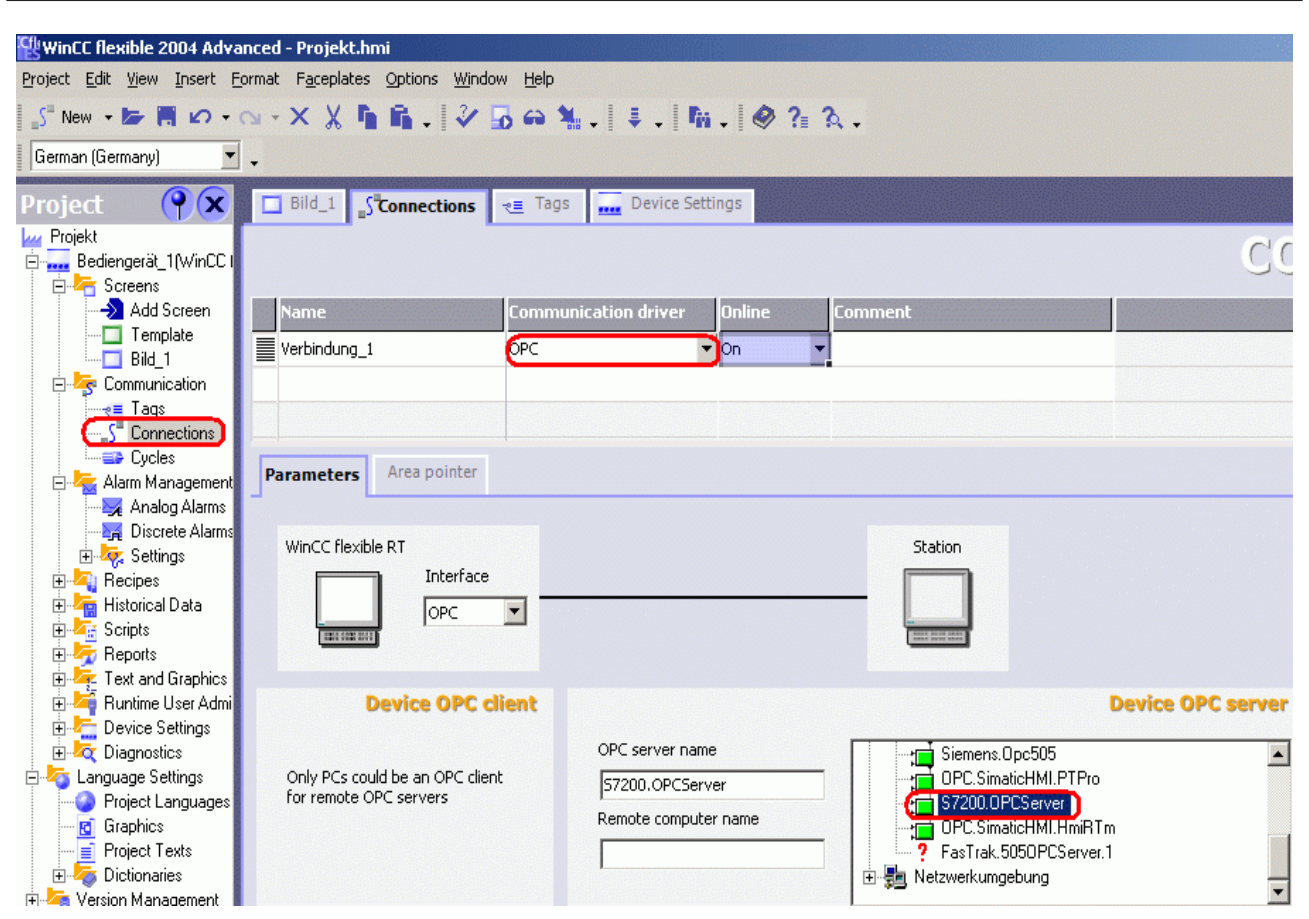

FIGURE 3. Win CC software programming view.

[26] shows the architecture, its implementation and testing of OLE for process control on data access specification. In OPC also known as ole for process control, we have the following things

- It can possibly provide connectivity up to 8 coexistent connection

- It has ability to use symbols directly from the STEP 7-Micro/WIN project

- It has a full backup of all the sets of S7-200 data types

- It also allows dead band parameters such as Engineering Units

- In it, a "TEST CLIENT" is also provided in order to have a quick and easy way to test any link live

- It has ability to work in almost six different languages such as Spanish, Chinese, German, English, Italian, and French

- It also includes samples work projects with popular clients

- In its helps system documentation is also given which can be used as hard or soft copy as manual

- Available as an OEM license version for OEM convenience

\subsection{Cogent Hub SCADA}

Here Cogent Hub Scada is facilitating our system with connecting, storing, integrating of data and displaying of data in real time scenario. We are able to build a complete system, or argument installed or existing systems. A simple HMI view after programming is shown in 


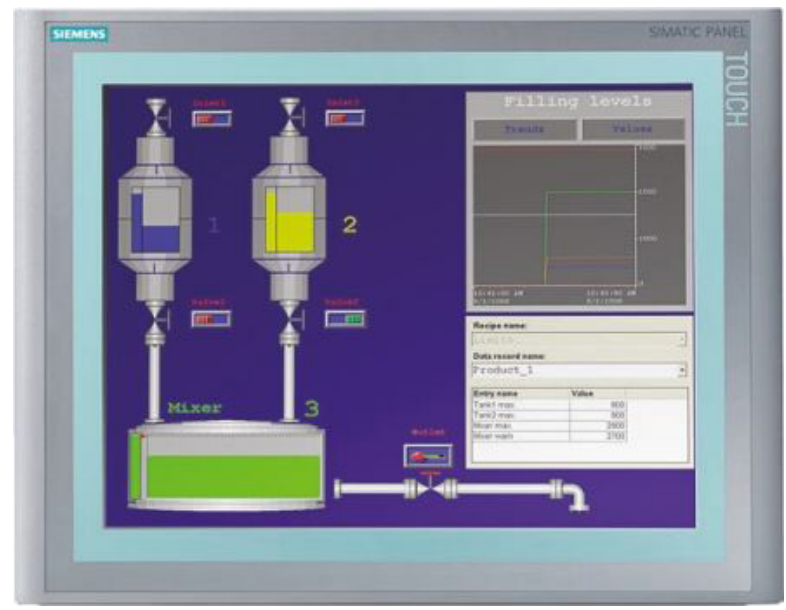

FIGURE 4. HMI screen.

Figure 4. We can easily link from any virtual source to or live data while using individual, modular component. All the data which are visible to the user can be integrated into a common data set. After that, we can create web pages to see and make a bridge with live process. We can store data for analyzing or archives as well as we can send notifications.

\section{Result}

For assessment of our suggested design, we have selected five different water bottles filling companies with names as Ali and Son, Refiller, Water, Ahsan, and OZ2 Water. These are some local companies having a small number of workers $50,20,33,15$, and 10, respectively. These companies are found in Malir and kala board district of Karachi. Table 1 shows the total number of users and choice of their users.

Table 1 shows the interest of the workers, working in above-mentioned companies, according to the three choices location, website and phone. In Figure 5, we get the idea that more people are interested in using the website than working on location and less people want to use the phone for such purpose. Figure 6 shows the overall and separately percentage of three choices likeness by the worker of the companies.

TABLE 1. Different company's user choice

\begin{tabular}{lcccc}
\hline $\begin{array}{l}\text { Method of use/ } \\
\text { company name }\end{array}$ & $\begin{array}{c}\text { Total number of } \\
\text { users }\end{array}$ & $\begin{array}{c}\text { User on } \\
\text { location }\end{array}$ & Using website & $\begin{array}{c}\text { Using } \\
\text { phone }\end{array}$ \\
\hline Ali Son & 44 & 17 & 15 & 12 \\
Refiller & 20 & 11 & 8 & 1 \\
Water & 33 & 1 & 28 & 4 \\
Ahsan & 15 & 0 & 7 & 8 \\
OZ2 Water & 10 & 6 & 4 & 0 \\
\hline
\end{tabular}




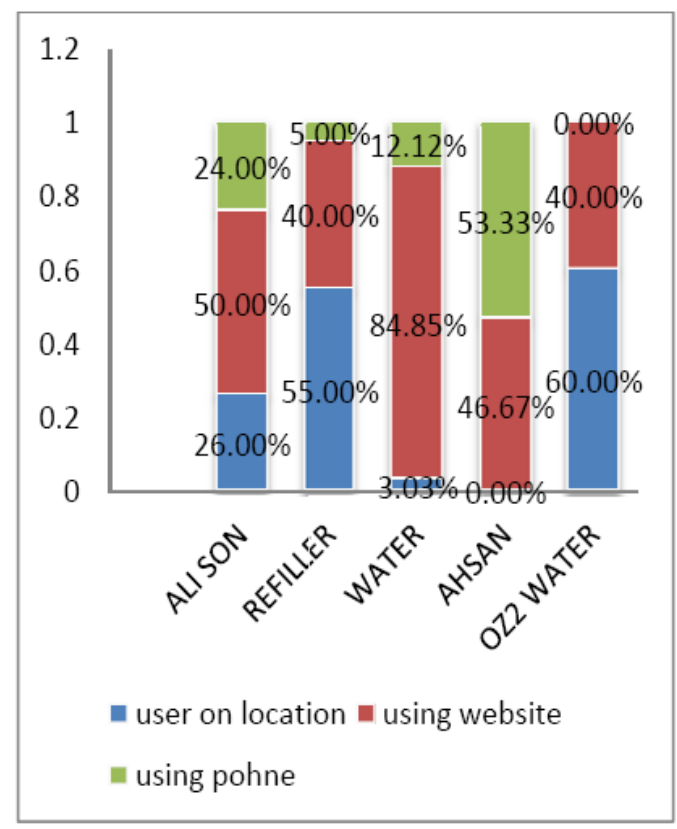

FIGURE 5. Choice wise percentage.

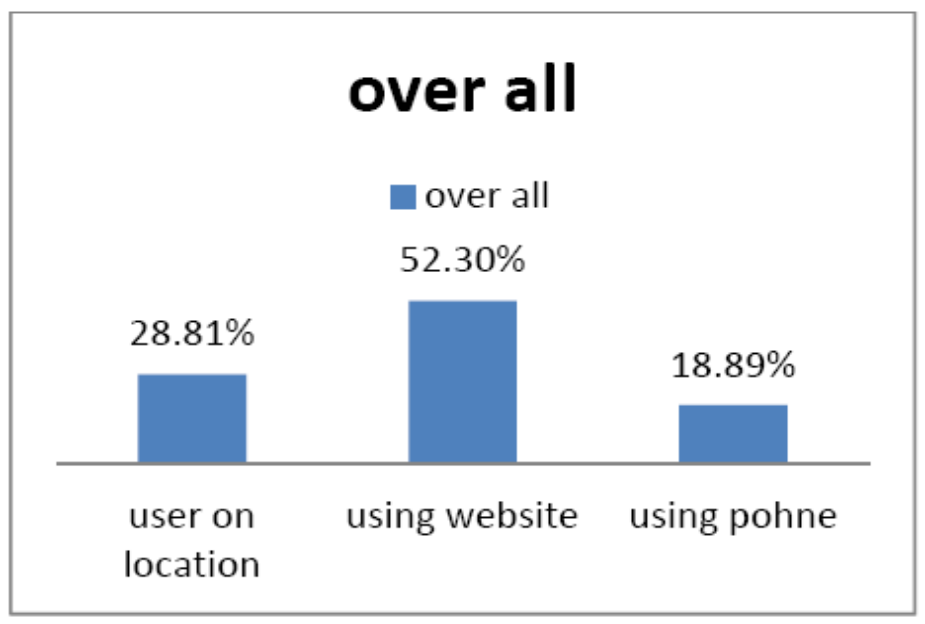

FIGURE 6. Overall percentage.

\section{Conclusion}

The control system what shown in our project was a prototype. Installing this system can be very easy, after modification to different industrial needs. There will be no pressure on workers of the industries especially employed in a dangerous vicinity of operating machines. This system helps in upgrading the security system and reducing time lose and health issues etc. In the proposed implemented hardware system, we have taken inputs from ten 
different devices. Anyone link to this system can view its live input or data status, or control it via using any simple PC or smart phone. This process is monitored and controlled over cloud using Wi-Fi device. An authorized person will get an update whenever there is any change in input via message on a smart phone or via email, link to the system, generated by the system. For the purpose of getting an overview about the usage and advantage of the product, we conduct a survey. In this survey, we visit different organization that are producing or using some liquid as their final product or raw data respectively. We get positive results as shown in Table 1 more number of persons per organization agree to upgrade the system and install this product as part of their organization. At the starting point till now, we conclude that the project gives full accuracy at its output. HMI provide, convincing the operator to get the visual view. The basic purpose of this project is to resolve the problem which is faced by the operator during controlling. It is designed as a compact to the previous. The project can manually as well as automatically operate all the parameters such as (flow, pressure, temperature \& level) beneficial for the operator. This project can be used as vast technology in the industries.

\section{References}

1. Tariq F, Rashid M, Khan MN. Implementation of smart homes and industrial automation system with secure communication over GSM. Universal Journal of Electrical and Electronic Engineering. 2015; 3(4), 10.

2. Sharma AK, Choubey KK, Sharma M. Industrial automation using 8051 microcontroller. International Journal of Advanced Engineering Research and Technology. 2015; 361, 364.

3. Madan V, Reddy SR. GSM-bluetooth based remote monitoring and control system with automatic light controller. International Journal of Computer Applications. 2012; 46(1), 20-28.

4. Role of automation in manufacturing industries. https://www.researchgate.net/ publication/325335307_ROLE_OF_AUTOMATION_IN_MANUFACTURING_ INDUSTRIES. Date accessed: 05/2018.

5. Influencing factors for implementing automation in manufacturing businesses-a literature review. https://repository.lboro.ac.uk/articles/Influencing_factors_for_implementing automation_in_manufacturing_businesses_a_literature_review/9554552. Date accessed: 2016.

6. Meenu JT. Automation and integration of industries through computer vision systems. International Journal of Information and Computation Technology. 2013; 3(9), 963-970.

7. Gade AH. A survey paper on cloud computing and its effective utilization with virtualization. International Journal of Scientific \& Engineering Research. 2013; 4(12), 357-363.

8. Kumar S, Goudar RH. Cloud computing-research issues, challenges, architecture, platforms and applications: a survey. International Journal of Future Computer and Communication. 2012; $1(4), 356$.

9. Research agenda in cloud technologies. https://arxiv.org/abs/1001.3259. Date accessed: $19 / 01 / 2010$.

10. Prasad MR, Naik RL, Bapuji V. Cloud computing: research issues and implications. International Journal of Cloud Computing and Services Science. 2013; 2(2), 134.

11. Kaur N, More S, Revanwar K, Kolapkar S. Industrial environment monitoring and controlling system using android application. Imperial Journal of Interdisciplinary Research (IJIR). 2016; 2(6), 515-517. 
12. Maqbool S, Ahmed Lone S. Monitoring system using GSM. International Journal of Computer Applications. 2015; 117(10), 28-31.

13. Tyagi N, Joshi A, Singh S. A comparative approach to remote home security system based on wireless system network and GSM. International Journal of Scientific \& Engineering Research. $2013 ; 4(6), 2437-2446$.

14. Javaid N, Sharif A, Mahmood A, Ahmed S, Qasim U, Khan ZA. Monitoring and controlling power using zigbee communications. In: 2012 seventh international conference on broadband, wireless computing, communication and applications. 2012; 608-613.

15. Teymourzadeh R, Ahmed SA, Chan KW, Hoong MV. Smart GSM based home automation system. In: 2013 IEEE conference on systems, process \& control (ICSPC). 2013; 306-309.

16. Azid SI, Sharma BN. Intelligent home: SMS based home security system with immediate feedback. World Academy of Science, Engineering and Technology. 2012; 72, 934-937.

17. Steenbruggen J, Borzacchiello MT, Nijkamp P, Scholten H. Mobile phone data from GSM networks for traffic parameter and urban spatial pattern assessment: a review of applications and opportunities. Geo Journal. 2013; 78(2), 223-243.

18. T. Dillon, C. Wu, and E. Chang, "Cloud Computing: Issues and Challenges. In: 24th IEEE international conference on advanced information networking and applications (AINA). 2010; 27-33.

19. Foster I, Zhao Y, Raicu I, Lu S. Cloud computing and grid computing 360-degree compared. In: Grid computing environments workshop (GCE '08). 2008; 1-10.

20. Inside one firm's private cloud journey. https://www.cio.com/article/2423453/inside-one-firms-private-cloud-journey.html. Date accessed: 28/10/2009.

21. Birman K, Chockler G, van Renesse R. Toward a cloud computing research agenda. SIGACT News. 2009; 40(2), 68-80.

22. Victor E. Lauria, Lucena Jr. F, Payam Parvaresh. Voice-activated system to remotely control industrial and building automation systems using cloud computing. 978-1-4799-08646/13/\$31.00 @2013 IEEE.

23. Anindya Maiti, Sivanesan S. Cloud controlled intrusion detection and burglary prevention stratagems in home automation systems. 978-1-4673-1671-2/12/\$31.00 @2012 IEEE.

24. Eric Bauer. Cloud automation and economic efficiency. IEEE Cloud Computing co published by the IEEE CS and IEEE ComSoc March/April 2018 2325-6095/18/\$33.00 USD @2018 IEEE.

25. Vishal Kumar, Asif Ali Laghari, Shahid Karim, Muhammad Shakir, Ali Anwar Brohi. Comparison of fog computing \& cloud computing. International Journal of Mathematical Sciences and Computing, 2019; 1, 31-41. Published online January 2019 in MECS (http://www. mecs-press.net). DOI: 10.5815/ijmsc.2019.01.03

26. Zhihao Ling, Weibin Chen, Jinshou Yu. Research and implementation of OPC server based on data access specification. Proceedings of the 5th world congress on intelligent control and automation, June 15-19, 2004, Hangzhou, P.R. China.

27. Memon MA, Soomro S, Jumani AK, Kartio MA. Big data analytics and its applications. arXiv preprint arXiv:1710.04135. 2017 Oct 9.

28. Rehman HA, Soomro AS, Surahio FA, Jumani AK. Implementation of Library management system using radio frequency identification technology in Sindh libraries. International Journal of Computer Science and Information Security (IJCSIS). 2016; 14(7).

29. Jumani A, Mahar J, Surahio F, Mahar M, Mahesar H, Talpur S. Destroy messages: design and development of software tool for WhatsApp. Sindh University Research Journal-SURJ (Science Series). 2016; 48(2). 
30. Memon M, Jumani A, Koondhar M, Memon M, Memon A. A technique to differentiate clustered operating systems. Sindh University Research Journal (Science Series). 2018; 50(3D), 89-94.

31. Surahio FA, Jumani AK, Talpur S. An approach to accept input in text editor through voice and its analysis, designing, development and implementation using speech recognition. International Journal of Computer Science and Network Security (IJCSNS). 2016; 16(3), 14.

32. Laghari AA, Memon MS, Pathan AS. RFID based toll deduction system. International Journal of Information Technology and Computer Science. 2012; 4, 40-46.

33. Laghari AA, He H, Shafiq M, Khan A. Assessing effect of cloud distance on end user's quality of experience (QoE). In: 2016 2nd IEEE international conference on computer and communications (ICCC). IEEE. 2016;500-505. 